Disclosure of Interests: None declared

DOI: 10.1136/annrheumdis-2019-eular.4906

\section{THU0281 SALIVARY GLAND ULTRASOUND FINDINGS ARE ASSOCIATED WITH CLINICAL AND SEROLOGIC FEATURES IN PRIMARY SJÖGREN'S SYNDROME PATIENTS}

Joana Silva ${ }^{1}$, Daniela Faria ${ }^{1}$, Joana Neves ${ }^{2}$, Marcos Cerqueira ${ }^{2}$, Joana Rodrigues ${ }^{1}$, Soraia Azevedo ${ }^{1}$, Sérgio Alcino ${ }^{1}$, José Tavares-Costa ${ }^{1}$, Carmo Afonso ${ }^{1}$, Daniela Peixoto ${ }^{1}$, Filipa Teixeira ${ }^{1} .{ }^{1}$ Unidade Local de Saúde do Alto Minho, Rheumatology, Ponte de Lima, Portugal; ${ }^{2}$ Hospital de Braga, Rheumatology, Braga, Portugal

Background: Primary Sjögren's syndrome (pSS) is a multisystem immunemediated disease characterized by hypofunction of salivary and lacrimal glands and possible multi-organ systemic manifestations. Over the past years, three sets of diagnostic criteria have been proposed, but none included salivary gland ultrasound (SGUS). However, SGUS has been recently applied for diagnosis and there are some reports regarding the correlation of SGUS findings with immunological and serological features in pSS patients $(1,2)$.

Objectives: To investigate the association of SGUS fndings with clinical and analytical features of pSS patients.

Methods: A total of 54 patients diagnosed with pSS, fulfilling both the 2016 ACR/EULAR and 2002 AECG criteria for the disease, followed-up at our Rheumatology department, underwent SGUS evaluation. The parenchymal homogeneity of bilateral parotid and submandibular glands was graded using a score of 0 (normal) to 4 (gross inhomogeneity). Patients were classified into two groups according to the highest US score obtained. The grades 1 and 2 were considered to be normal and grades 3 and 4 to represent pathological SGUS findings. Demographics (age, sex and disease duration), European League Against Rheumatism Sjögren's Syndrome Disease Activity Index (ESSDAl) and laboratorial data (erythrocyte sedimentation rate, autoantibodies, rheumatoid factor, hypergammaglobulinemia, $\beta 2$-microglobulin and complement levels) were collected and compared between the two SGUS groups. The association between SGUS and these data was explored by multivariable analysis. Statistical significance was defined as $p<0.05$.

Results: The mean age of patients was $57.5 \pm 13.3$ years and median disease duration was 5.0 [IQR (2.75-11.25)]. The majority of the study population were women $(96 \%)$ and $35 \%(19 / 54)$ had pathological SGUS findings.

Differences between the group with pathological SGUS versus the group with normal SGUS are depicted in table 1.

Multivariate logistic regression revealed that anti-SSB ([OR] $=6.6,95 \%$ [Cl] 1.7 to $25.8, p=0.006$ ) was independently associated with the presence of pathological features in SGUS.

Table 1. Comparison of demographics, clinical and serologic features of pSS according to SGUS.

\begin{tabular}{lccc}
\hline & $\begin{array}{c}\text { Pathological SGUS } \\
(\mathbf{n}=\mathbf{1 9 )}\end{array}$ & $\begin{array}{c}\text { Normal } \\
\text { SGUS } \\
(\mathbf{n}=\mathbf{3 5})\end{array}$ & $\begin{array}{c}\mathbf{P} \\
\text { value }\end{array}$ \\
\hline Mean age, years & $54.3 \pm 12.6$ & $59.2 \pm 13.5$ & 0.497 \\
Mean disease duration, years & $6.6 \pm 6.1$ & $7.7 \pm 5.2$ & 0.976 \\
ESSDAI (IQR) & $2.2(0-5)$ & $0.9(0-1)$ & $\mathbf{0 . 0 4 4}$ \\
Mean Sedimentation rate, mm & $36.3 \pm 22.1$ & $22.7 \pm 15.8$ & 0.160 \\
Antinuclear antibody, $\mathbf{n}$ (\%) & $19(100)$ & $32(91.4)$ & 0.544 \\
Anti-SSA, $\mathbf{n}$ (\%) & $18(94.7)$ & $27(77.1)$ & 0.137 \\
Anti-SSB, $\mathbf{n}(\%)$ & $14(73.7)$ & $9(25.7)$ & $\mathbf{0 . 0 0 1}$ \\
Rheumatoid factor, $\mathbf{n}$ (\%) & $14(73.7)$ & $14(40.0)$ & $\mathbf{0 . 0 1 8}$ \\
Hypergammaglobulinemia, $\mathbf{n}$ (\%) & $12(63.2)$ & $14(40)$ & 0.104 \\
Mean $\boldsymbol{\beta} 2-$-microglobulin, $\mathbf{m g} / \mathbf{L}$ & $2.9 \pm 0.9$ & $2.2 \pm 0.7$ & 0.378 \\
Mean Complement 3, mg/dL & $115.1 \pm 28.9$ & $120.7 \pm 24.5$ & 0.938 \\
Mean Complement 4, mg/dL & $21.6 \pm 6.0$ & $21.9 \pm 8.1$ & 0.165 \\
Hydroxychloroquine treatment, $\mathbf{n}$ & $15(78.9)$ & $21(60.0)$ & 0.229 \\
(\%) & & & \\
\hline
\end{tabular}

Conclusion: In our study, pathological US findings were associated with higher disease activity and positivity for rheumatoid factor and anti-SSB. Additionally, anti-SSB antibody was strongly and independently associated with pathological US findings in the salivary gland of pSS patients. Further and larger studies are necessary to support these findings and include SGUS as part of the diagnostic criteria for Sjögren's syndrome.
REFERENCES:

[1] J-W Kim, et al. Salivary gland ultrasonography findings are associated with clinical, histological, and serologic features of Sjögren's syndrome. Scand J Rheumatol 2018;00:1-8.

[2] J. Nieto-González et al. Salivary gland ultrasound is linked to the autoimmunity profile in patients with primary Sjögren's syndrome. Journal of International Medical Research 2018; 0(0) 1-11.

Disclosure of Interests: None declared

DOI: 10.1136/annrheumdis-2019-eular.7217

\section{THU0282 ULTRASOUND FINDINGS IN THE SALIVARY GLANDS IN A COHORT OF PATIENTS WITH SUSPECTED SJÖGREN'S SYNDROME}

Viktoria Fana, Uffe Møller Døhn, Lene Terslev. Rigshospitalet-Glostrup, Center for Rheumatology and Spine Diseases, Copenhagen, Denmark

Background: Ultrasound has been shown to be a promising tool in the evaluation of salivary glands for parenchyma changes with the potentia to improve diagnosis. The changes range from mild inhomogeneity of the glandular tissue to large vesicular changes almost eliminating all normal glandular tissue. American-European Consensus Group (AECG) classification criteria for SS are often used diagnostically (1).

Objectives: To describe ultrasound findings in salivary glands (SGUS) in a cohort of patients with suspected Sjögren's syndrome (SS) and assess their positive and negative predictive value for the diagnosis.

Methods: 191 consecutive patients with suspected SS (ocular and/or oral dryness) referred to the department of Rheumatology between March 2017 and March 2018 were evaluated by SGUS as part of the initial evaluation. All had unstimulated sialometry, Schirmer's test and laboratory test done (including autoantibodies (ANA screening, Rheumatoid facto and anti-cyclic citrullinated peptide, anti-Ro/SSA and anti-La/SSB), and screenings test for hepatitis $B+C$ ). In doubtful cases, a minor salivary gland (MSG) biopsy was performed. SGUS was performed with a GE Logiq E9 equipped with a linear ML6-15 probe and included grey-scale evaluation of the submandibular and parotid gland bilaterally. SGUS was considered abnormal when moderate to severe inhomogeneity with anechoic or hypoechoic areas was present in at least one gland.

Results: 63 patients were diagnosed with SS according to the AECG classification criteria - 57 patients with primary SS, 6 with secondary SS 128 patients with sicca symptoms did not fulfill AECG criteria for SS and none were diagnosed with SS based on other parameters. Demographic data for the cohort is shown in table 1. 55 patients had MSG biopsy performed. The SGUS examination and evaluation was performed in less than $15 \mathrm{~min}$ per patient. The sensitivity of SGUS is 0.51 and the specificity 0.88 ; the PPV of SGUS for the SS diagnosis was 0.68 and the NPV was 0.78

The sensitivity of SGUS for positive MSG biopsy was 0.29 and the specificity 0.82 - the PPV was 0.50 and the NPV was 0.65 ; for abnormal sialometry the sensitivity of SGUS was 0.32 and the specificity 0.82 the PPV for SGUS was 0.64 and NPV was 0.55 .

Table 2 shows the association between SGUS and final diagnosis, MSG biopsy and sialometry, respectively.

Abstract THU0282 -Table 1

\begin{tabular}{|l|l|l|l|}
\hline Table 1 & Primary SS & Secondary SS & $\begin{array}{l}\text { Not fulfilling SS } \\
\text { classification criteria }\end{array}$ \\
\hline Female/male, $n$ & $55 / 5$ & $6 / 0$ & $101 / 27$ \\
\hline Mean age, years (range) & $56(27-83)$ & $56(42-68)$ & $56(17-86)$ \\
\hline $\begin{array}{l}\text { Positive Shirmers test, } \\
\mathrm{n}(\%)\end{array}$ & $26(46 \%)$ & $2(33 \%)$ & $6(5 \%)$ \\
\hline $\begin{array}{l}\text { Positive Sialometry } \\
\mathrm{n}(\%)\end{array}$ & $44(77 \%)$ & $6(100 \%)$ & $45(35 \%)$ \\
\hline Anti-RO/SSA, $n(\%)$ & $48(84 \%)$ & $1(17 \%)$ & $37(29 \%)$ \\
\hline Anti-La/SSB, n(\%) & $18(32 \%)$ & $0(0 \%)$ & $6(5 \%)$ \\
\hline
\end{tabular}

$n=$ number, $S S=$ Sjögren's Syndrome

\begin{tabular}{|l|l|l|l|l|l|l|}
\hline Table 2 & $\begin{array}{l}\text { Fulfilling SS } \\
\text { classification } \\
\text { criteria } \\
\mathrm{n}(\%)\end{array}$ & $\begin{array}{l}\text { Not fulfilling } \\
\text { SS } \\
\text { classification } \\
\text { criteria } \\
\mathrm{n}(\%)\end{array}$ & $\begin{array}{l}\text { Positive } \\
\text { MSG biopsy }\end{array}$ & $\begin{array}{l}\text { Negative } \\
\text { MSG biopsy }\end{array}$ & $\begin{array}{l}\text { Positive } \\
\text { sialometrx } \\
\text { for SS| }\end{array}$ & $\begin{array}{l}\text { Negative } \\
\text { sialometrx } \\
\text { for SS }\end{array}$ \\
\hline $\begin{array}{l}\text { Positive } \\
\text { SGUS for SS } \\
\mathrm{n}(\%)\end{array}$ & $32(51 \%)$ & $15(12 \%)$ & $6(29 \%)$ & $6(18 \%)$ & $30(32 \%)$ & $17(18 \%)$ \\
\hline $\begin{array}{l}\text { Negative } \\
\text { SGUS for SS } \\
\mathrm{n}(\%)\end{array}$ & $31(49 \%)$ & $113(88 \%)$ & $15(71 \%)$ & $28(82 \%)$ & $64(68 \%)$ & $80(82 \%)$ \\
\hline
\end{tabular}

Conclusion: SGUS has a high specificity but poor sensitivity for the SS diagnosis with a good NPV and a high specificity for positive MSG 
biopsy and positive sialometry. SGUS is a feasible method for the evaluation of structural changes in the salivary gland and may aid in the diagnosis and classification of SS.

\section{REFERENCE:}

[1] Vitali C, Bombardieri S, Jonsson R, Moutsopoulos HM, Alexander EL, Carsons SE, et al. Classification criteria for Sjögren's syndrome: a revised version of the European criteria proposed by the American-European Consensus Group. Ann Rheum Dis. 2002;61:554-8.

Disclosure of Interests: Viktoria Fana: None declared, Uffe Møller Døhn Speakers bureau: Speakers fee from Eli Lilly, Novartis and Roche, Lene Terslev Speakers bureau: Speakers fee from : Roche, Novartis, Pfizer, MSD, BMS, Celgene

DOI: 10.1136/annrheumdis-2019-eular.7409

\section{THU0283 PATIENT ACCEPTABLE SYMPTOMS STATE (PASS) QUESTIONNAIRE APPLICATION IN THE COHORT OF SLE PATIENTS FROM THE SPANISH SOCIETY OF RHEUMATOLOGY (RELESSER): ASSOCIATION WITH ACTIVITY INDEX}

Tomas Vazquez Rodriguez ${ }^{1}$, Iñigo Rua Figueroa ${ }^{2}$, Victor Del Campo Pérez ${ }^{3}$, J. Narváez ${ }^{4}$, Francisco J López-Longo ${ }^{5}$, María Galindo-Izquierdo ${ }^{6}$, Jaime CalvoAlen $^{7}$, Antonio Fernandez-Nebro ${ }^{8}$, Juan Ovalles ${ }^{9}$, Pilar Rubio Muñoz ${ }^{10}$, Eva Tomero Muriel ${ }^{11}$, Coral Mouriño Rodríguez ${ }^{3}$, Esther Uriarte Isacelaya ${ }^{12}$, Angela Pecondon-Español ${ }^{13}$, Mercedes Freire González ${ }^{14}$, Ricardo Blanco ${ }^{15}$ Marian Gantes Mora ${ }^{16}$, Mónica lbañez Barcelób ${ }^{77}$, Carlos A. Montilla-Morales ${ }^{18}$, Jose M Pego-Reigosa ${ }^{3}$, RELESSER (Spanish Society of Rheumatology Lupus Registry). ${ }^{1}$ HOSPITAL LUCUS AUGUSTI, LUGO, Spain; ${ }^{2}$ HOSPITAL GRAN CANARIA DR NEGRIN, Gran Canaria, Spain; ${ }^{3}$ COMPLEJO HOSPITALARIO UNIVERSITARIO DE VIGO, Vigo, Spain; ${ }^{4}$ HOSPITAL DE BELLVITGE, Barcelona, Spain; ${ }^{5}$ HOSPITAL GENERAL UNIVERSITARIO GREGORIO MARAÑÓN, MADRID, Spain; ${ }^{6}$ HOSPITAL UNIVERSITARIO 12 DE OCTUBRE, Madrid, Spain: ${ }^{7}$ HOSPITAL UNIVERSITARIO ARABA, Alava, Spain; ${ }^{8}$ HOSPITAL REGIONAL UNIVERSITARIO DE MÁLAGA, Malaga, Spain; ${ }^{9}$ HOSPITAL GENERAL UNIVERSITARIO GREGORIO MARAÑÓN, Madrid, Spain; ${ }^{10} \mathrm{HOSPITAL}$ GERMANS TRIAS I PUJOL, Badalona, Spain; ${ }^{11}$ HOSPITAL DE LA PRINCESA, Madrid, Spain; ${ }^{12}$ HOSPITAL DE DONOSTIA, Donostia, Spain; ${ }^{13} \mathrm{HOSPITAL}$ MIGUEL SERVET, Zaragoza, Spain; ${ }^{14}$ HOSPITAL JUAN CANALEJO A CORUÑA, A Coruña, Spain; ${ }^{15}$ HOSPITAL MARQUÉS DE VALDECILLA, Santander, Spain; ${ }^{16}$ HOSPITAL UNIVERSITARIO DE CANARIAS, Las Palmas de Gran Canaria, Spain; ${ }^{17}$ HOSPITAL SON LLÀTZER, Mallorca, Spain; ${ }^{18}$ HOSPITAL CLÍNICO UNIVERSITARIO SALAMANCA, Salamanca, Spain

Background: Little is known about the patient related outcomes and disease activity in systemic lupus erythematosus. Damage and impact are issues that have not been associated with activity in lupus previously. Objectives: In a large cohort of systemic lupus erythematosus (SLE) patients, to evaluate the association between a Patient Acceptable Symptom State (PASS) and three different domains of the disease: activity, damage and impact of SLE on patients' lives

Methods: Cross-sectional study of 1,364 SLE (ACR 97 Criteria) patients from the Spanish Society of Rheumatology Lupus Registry (RELESSER) Patients were clinically assessed by the physicians, who collected data about demographics, clinical manifestations, laboratory features and therapies. SLE activity was assessed by using the SLEDAI (SLE Disease Activity Index). The Systemic Lupus International Collaborating Clinics/ American College of Rheumatology Damage Index (SLICC/ACR DI) was used to measure damage accrual. The impact of SLE on patients' lives was evaluated by using the Lupus Impact Tracker (LIT). The PASS question "Considering all the different ways your disease is affecting you, if you would stay in this state for the next months, do you consider that your current state is satisfactory?" was answered in a dichotomized way: yes/no. Measures of central tendency and spread were used to describe responses and T-test was used to evaluate the independence between PASS and the other questionnaires and indices.

Results: Mean age (years) \pm S.D. of the 1,364 patients included in the study was $49.9 \pm 13.3$; $90.3 \%$ were female and $94.9 \%$ were Caucasian. In the total of patients, $979(71.8 \%)$ were in PASS. Patients in PASS had significantly lower activity (SLEDAI Score) than those not in PASS $(2.4 \pm 3.2$ vs. $3.0 \pm 3.9$, respectively; $p=0.007)$. The SLICC/ACR DI was significantly lower in the group of patients in PASS compared to those without PASS $(0.64 \pm 1.1$ vs. $0.81 \pm 0.21$, respectively; $p=0.022)$. SLE had a significantly lower impact on patients in PASS in comparison to those without PASS (LIT Score: $8.47 \pm 7.5$ vs. $19.8 \pm 8.34$, respectively; $\mathrm{p}=0.001)$.
Conclusion: In the largest observational European Registry of SLE patients, PASS was associated with other domains of the disease: activ ity, damage and impact on patients' life. PASS is a simple and reliable patient-reported outcome that can be a useful tool to evaluate patients well-being.

Disclosure of Interests: Tomas Vazquez Rodriguez: None declared, Iñigo Rua Figueroa: None declared, Victor Del Campo Pérez: None declared J. Narváez Consultant for: Bristol-Myers Squibb, Francisco J López-Longo: None declared, María Galindo-Izquierdo: None declared, Jaime CalvoAlen: None declared, Antonio Fernandez-Nebro: None declared, Juan Ovalles: None declared, Pilar Rubio Muñoz: None declared, Eva Tomero Muriel: None declared, Coral Mouriño Rodríguez: None declared, Esthe Uriarte Isacelaya: None declared, Angela Pecondon-Español: None declared, Mercedes Freire González: None declared, Ricardo Blanco Grant/research support from: Abbvie, MSD, and Roche, Consultant for: Abbvie, Pfizer, Roche, Bristol-Myers, Janssen, Speakers bureau: Abbvie, Pfizer, Roche, Bristol-Myers, Janssen, Marian Gantes Mora: None declared, Mónica Ibañez Barceló: None declared, Carlos A. MontillaMorales: None declared, Jose M Pego-Reigosa: None declared DOI: 10.1136/annrheumdis-2019-eular.1945

\section{THU0284 WHAT DO HEMATOLOGICAL ABNORMALITIES TELL US IN SLE? RESULTS FROM TWO INDEPENDENT MULTICENTER EUROPEAN SLE COHORTS}

Sule Yavuz ${ }^{1}$, Dondu Cansu ${ }^{2}$, Dionisis Nikolopoulos ${ }^{3}$, Francesca Crisafulli ${ }^{4}$, Ana M Arantunes $^{5}$, Christina Adamichou ${ }^{6}$, Sara Reid ${ }^{1}$, Chiara Satgnaro ${ }^{7}$, Laura Andreoli ${ }^{8}$, Angela Tincani ${ }^{8}$, Maria Moraes-Fontes ${ }^{5}$, George Bertsias ${ }^{6}$,

Marta Mosca ${ }^{9}$, Dag Leonard ${ }^{1}$, Antonis Fanouriakis ${ }^{3}$, Lars Ronnblom ${ }^{1}$, Swedishsle Network ${ }^{10}$, The Authors would like to thank Dr. Koray Tascilar for his technical assistance. ${ }^{1}$ Uppsala University, Uppsala, Sweden; ${ }^{2}$ Eskişehir Osmangazi University Hospital, Eskişehir, Turkey; " "Attikon" University Hospital, Athens, Greece; ${ }^{4}$ Rheumatology and Clinical Immunology Unit, Spedali Civili and University of Brescia, Bresica, Italy; ${ }^{5}$ Centro Hospitalar de Lisboa Centra, Lisboa, Portugal; ${ }^{6}$ University of Crete, Crete, Greece: ${ }^{7}$ University of Pisa, Pisa, Italy, ${ }^{8}$ Spedali Civili and University of Brescia, Brescia, Italy; ${ }^{9}$ Rheumatology Unit, Department of Clinical and Experimental Medicine, University of Pisa, Pisa, Italy; ${ }^{10}$ SWedishSLENetwork, Stockholm, Sweden

Background: Detailed analysis of hematological manifestations are limited and their clinical impact on disease remain obscure.

Objectives: To scrutinize factors associated with different hematological abnormalities (HA) in SLE patients and their impact on infections, bleeding and damage accrual.

Methods: A dataset (GIPTSLE) originated from SLE patients in Europe was studied. The dataset consisted of six monthly visits of each patients for at least 2 years. Results were compared with another well-established SLE cohort from Sweden (Swedish SLE network). Patients in both cohorts fulfilled the ACR1982 SLE criteria. Variables collected at each visit included $\mathrm{CBC}$, presence or absence of haemolytic anemia, all domains of SLEDAI-2K, medications, infection or bleeding episodes, Systemic Lupus International Collaborating Clinics/ACR damage index (SDI). $\mathrm{HA}$ occurred at the beginning or during follow-up were defined according to the ACR criteria. HA was only considered in patients with no prior use of immunsuppressives or biologic agents at least 3 months before the first HA events. The Swedish confirmation cohort included all the variables of interest. We excluded all haematological domains from SLEDAI2K (aSLEDAl) for the analysis. Based on six monthly change in SDI, each visit was labelled either "damage transition"or "non-damage transition". Generalized estimating equations (GEE), multiple logistic regression, Chi-square test and independent samples $t$ test were used where it was appropriate.

Results: Of the 1430 visits of 286 patients analysed from the first cohort (89.5\% female, $95.8 \%$ Caucasian, $64.7 \%$ dsDNA positive) $60 \%$ had at least one HA. At the enrolment, the median (range) disease duration was 8 yrs (0-38), aSLEDAI-2K was $6(0-25)$ and SDI was $0(0-6)$. Upon GEE analysis, Iymphopenia was significant for $\mathrm{SDI}(\mathrm{OR}=2.5,1.0-5.9)$.Upon GEE analysis after further adjusting prednisolone exposure, HA found be significant for $S D I$ was thrombocytopenia $(O R=3.6,1.04-12.1)$ but no significant evidence for the dependence of this relationship on time. The effect of lymphopenia was attenuated. HR for bleeding was significant when platelets were below 50K ( $\mathrm{HR}=2.6,1.15-6.1)$ Of the 1395 patients analysed from the second set $(86.8 \%$ female, $93.0 \%$ Caucasian, 61.6 dsDNA positive), $63.4 \%$ had HA. At the last visit, the median (range) disease duration was 14yrs (1-65) and SDI was 1(0-14). Upon multiple regression analysis after adjusting age, sex and prednisolone exposure both thrombocytopenia $(\mathrm{OR}=2.2,1.3-3.6)$ and lymphopenia $(\mathrm{OR}=1.8,1.2$ 